\title{
Assessing Cross Laminated Timber (CLT) as an Alternative Material for Mid-Rise Residential Buildings in Cold Regions in China-A Life-Cycle Assessment Approach
}

\author{
Ying Liu ${ }^{1}$, Haibo Guo ${ }^{2}$, Cheng Sun ${ }^{2}$ and Wen-Shao Chang ${ }^{1, *}$ \\ 1 Department of Architecture and Civil Engineering, University of Bath, Bath BA2 7AY, UK; yl2497@bath.ac.uk \\ 2 School of Architecture, Harbin Institute of Technology, Harbin 150001, China; guohb@hit.edu.cn (H.G.); \\ suncheng@hit.edu.cn (C.S.) \\ * Correspondence: wsc22@bath.ac.uk \\ Academic Editor: Víctor Yepes \\ Received: 17 September 2016; Accepted: 13 October 2016; Published: 18 October 2016
}

\begin{abstract}
Timber building has gained more and more attention worldwide due to it being a generic renewable material and having low environmental impact. It is widely accepted that the use of timber may be able to reduce the embodied energy of a building. However, the development of timber buildings in China is not as rapid as in some other countries. This may be because of the limitations of building regulations and technological development. Several new policies have been or are being implemented in China in order to encourage the use of timber in building construction and this could lead to a revolutionary change in the building industry in China. This paper is the first one to examine the feasibility of using Cross Laminated Timber (CLT) as an alternative solution to concrete by means of a cradle-to-grave life-cycle assessment in China. A seven-storey reference concrete building in $\mathrm{Xi}^{\prime}$ an was selected as a case study in comparison with a redesigned CLT building. Two cities in China, in cold and severe cold regions ( $\mathrm{Xi}^{\prime}$ an and Harbin), were selected for this research. The assessment includes three different stages of the life span of a building: materialisation, operation, and end-of-life. The inventory data used in the materialisation stage was mostly local, in order to ensure that the assessment appropriately reflects the situation in China. Energy consumption in the operation stage was obtained from simulation by commercialised software IES ${ }^{\mathrm{TM}}$, and different scenarios for recycling of timber material in the end-of-life are discussed in this paper. The results from this paper show that using CLT to replace conventional carbon intensive material would reduce energy consumption by more than $30 \%$ and reduce $\mathrm{CO}_{2}$ emission by more than $40 \%$ in both cities. This paper supports, and has shown the potential of, CLT being used in cold regions with proper detailing to minimise environmental impact.
\end{abstract}

Keywords: Cross Laminated Timber (CLT); cold regions; cradle-to-grave; LCA

\section{Introduction}

The construction industry consumes about $40 \%$ of total energy worldwide and is responsible for nearly $36 \%$ of global $\mathrm{CO}_{2}$ emissions [1]. Without a doubt, the expansion of urban areas in China has accelerated energy consumption and a lack of energy efficiency measures for housing in China has made it worse. For example, some of the major cities in China have even higher carbon emissions per capita in comparison to those in the developed countries [2]. The government of China has set the target that $\mathrm{CO}_{2}$ emissions should be reduced by $40 \%-45 \%$ relative to 2005 by the end of 2020 [3,4]. Several government policies also support the development of timber use as an alternative construction material to more energy intensive materials such as concrete. In 2015, a government document was published 
which clearly states the intention of the government to promote using timber as a construction material for public buildings and housing in China [5]. The ambitious target of $\mathrm{CO}_{2}$ reduction set by the Chinese government requires collaboration between local and central governments, and it is not unusual for there to be disparities between the policies on paper and their actual implementation [6]. With development of new technology, new buildings are increasingly energy efficient and hence considerations of the environmental impact in selecting the construction materials is becoming more important [7]. Studies concerning the implementation of carbon emissions reductions are scarce in China. In particular, only very limited research takes the approach of reducing carbon emissions by altering current carbon-intensive construction materials. One of these limited research works, carried out by Gong et al., compared energy consumption and carbon emissions in scenarios using concrete, steel and timber as materials for frameworks in Beijing, and points out that concrete and steel frames would consume 30\% more energy compared to timber frames [8]. This echoes the conclusions of other researchers, such as Eriksson [9] and Gustavsson [10], both of whom point out that timber buildings consume less energy and reduce $\mathrm{CO}_{2}$ emissions during the life span of structures. The environmental benefit of using timber for construction is also pointed out by Guardigli [11].

Cross laminated timber (CLT) is considered a revolutionary engineered timber product that can change the building industry in a considerable way [12]. Its development started in Europe in the early 1990s, and in the last two decades it has experienced a double-digit growth rate [13] and is now widely used in timber constructions, particularly in multi-storey timber buildings. CLT is made of laminating several layers of timber lamellas, alternating the direction of the grain between layers, as seen in Figure 1, in order to gain strength in both directions and better stability in volume. There have been significant efforts to enhance efficiency in using CLT in construction. It can be used in different structural components, such as large span floors [14]. CLT buildings are normally considered to have better structural performance and this is supported by a large amount of research [15]. Some researchers also focus on enhancing the mechanical properties of CLT or using different materials in lamina $[16,17]$.

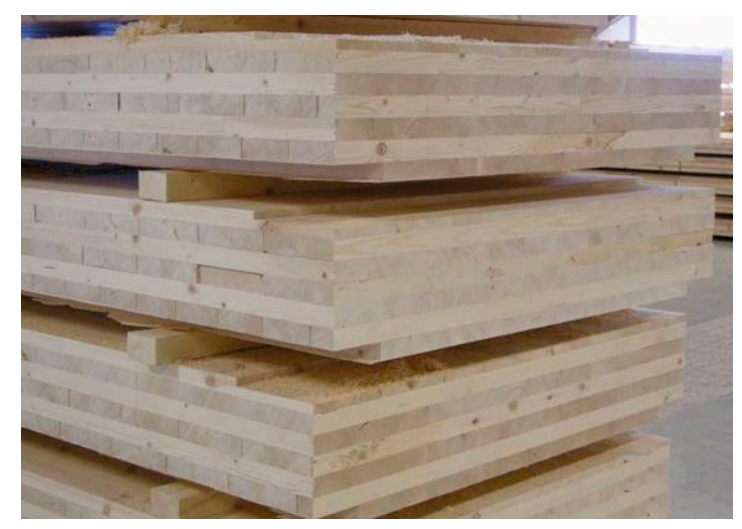

Figure 1. Cross laminated timber (CLT) panels.

CLT benefits from its suitability for prefabrication, fast erection and better quality control, and therefore it is reported that 8 out of 10 modern timber constructions over $25 \mathrm{~m}$ in height are built with CLT [18]. This phenomenon shows that CLT has the niche in timber structures of around this height. The first multi-storey CLT building was the Stadthaus project in Murray Grove of Hackney Borough, London. It is a residential building with an eight-storey CLT structure built on a Reinforced Concrete (RC) ground floor. It was the tallest timber structure at the time it was completed, but was later overtaken by the Forte project in Melbourne. Nowadays, the tallest CLT platform construction is the Dalston Lane project (Figure 2), a residential development in London, which is $33.8 \mathrm{~m}$ in height [19]. 


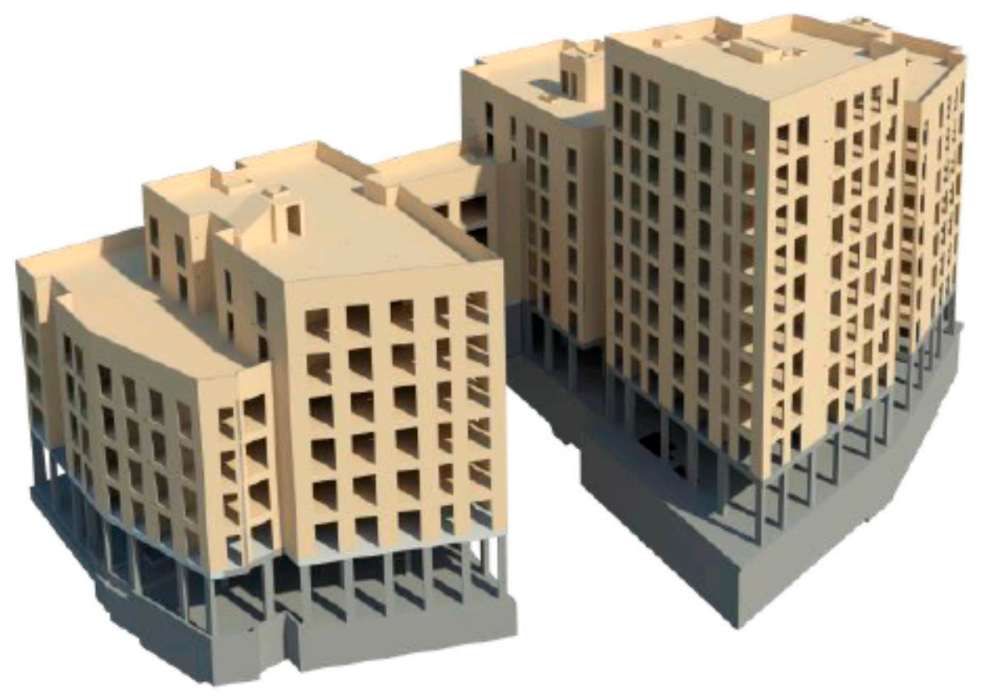

Figure 2. 3D structural model of Dalston Lane project [19].

Recent trends have considered wood to be a sustainable construction material and multi-storey CLT buildings are becoming common all over the world. With policy support from the Chinese government to promote the use of timber for construction, the issue of the lack of quantitative evidence for this argument needs to be addressed. This paper aims to compare and discuss the feasibility of using CLT in mid-rise residential housing to replace concrete ones in cold regions in China by means of a life-cycle assessment of energy consumption and carbon emissions.

\section{Description of the Case Studies Buildings and Environment}

\subsection{Weather Regions of Harbin and Xi'an}

In the Code for Design of Civil Buildings [20], China is divided into seven different climate regions. In this paper, to discuss the feasibility of using CLT to replace conventional building materials in cold regions, Harbin and Xi'an are selected for investigation. The former is the capital and largest city of Heilongjiang Province and is located in a severe cold region; the latter is the capital city of Shaanxi Province and is in a cold region as defined by building codes. The average temperatures of these two cities over the year are shown in Figure 3.

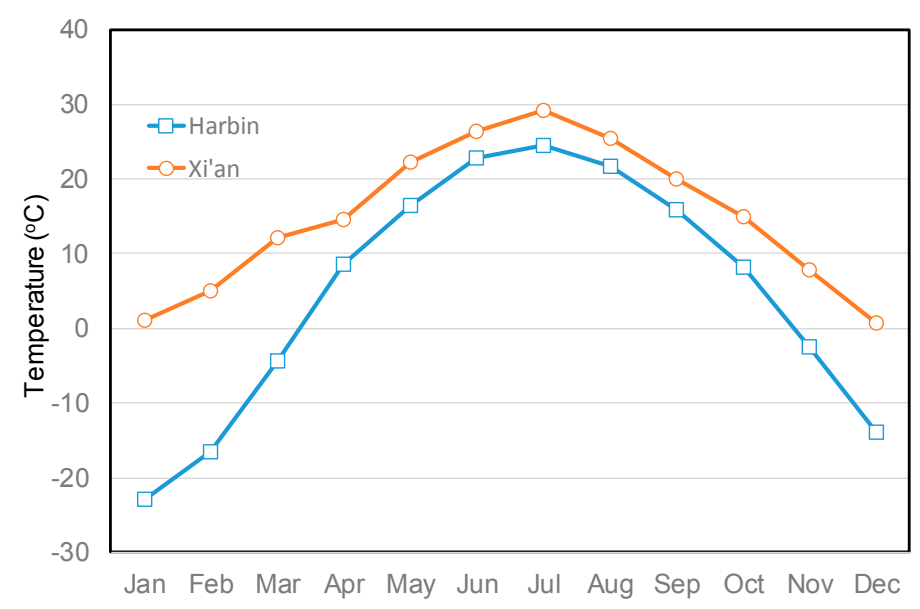

Figure 3. Average temperatures of $\mathrm{X}^{\mathrm{i}}$ an and Harbin throughout the year. 


\subsection{Concrete Structures}

In order to investigate the energy consumption and carbon emissions of a real concrete structure in different locations, we used a real building as a case study. The building is a seven-storey concrete structure, framed with brick infill walls supported by concrete foundations, and is located in a cold region. This is a common type of construction for residential housing in China. The ground floor is used for storage and the residential units start from the first floor. The building has a $2799.3 \mathrm{~m}^{2}$ area and the dimensions and relevant drawings are illustrated in Figure 4 The envelope design complies with requirements for residential building regulations for severe cold and cold regions in China [21].
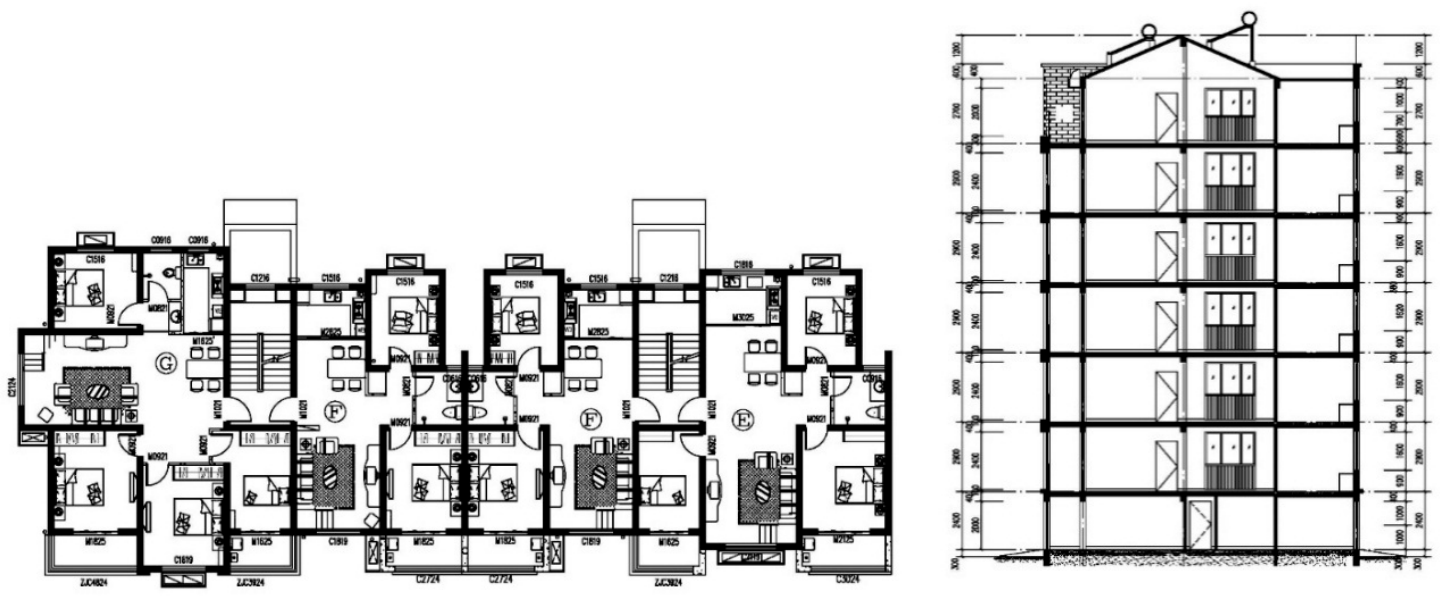

Figure 4. Plan and section drawings of selected building.

The details are redesigned in this construction, as though were located in Harbin (severe cold region) according to building regulations, to reflect the $U$-value required for this region. The details of floor and envelope of this case study located in Harbin and Xi'an are illustrated in Figure 5.

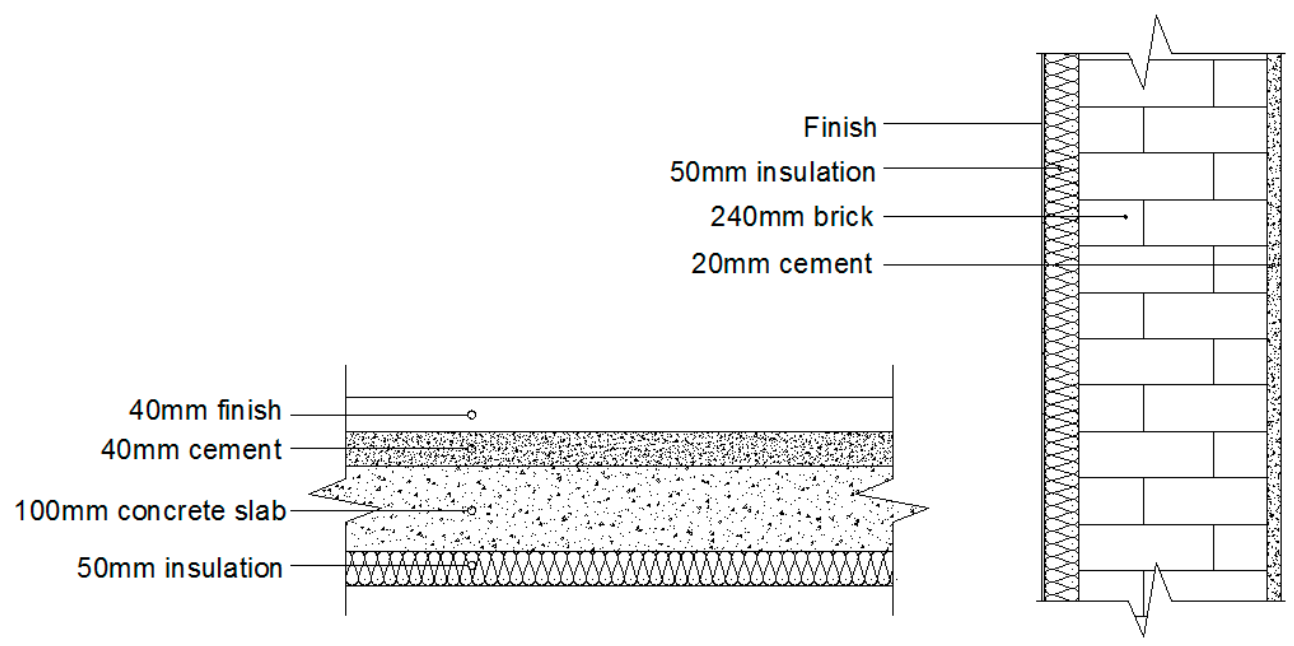

Figure 5. Details of floor and walls for concrete structures according to building regulation.

\subsection{CLT Substitution Design}

There are currently no provisions for CLT products in the current standard; there will be new chapters on CLT design and manufacturing included in the next revision of timber design standards in China. Therefore, in this paper, Eurocode 5 and relevant documents [22,23] are used to design CLT substitution structures, whilst the building envelopes are designed by the existing design standard [21]. 
The design strategy for the CLT substitution structure is not simply material replacement, but a proper dimension to support the structure. The dimensions, such as structural height, building orientations, gross area, and the opening, remain the same as for the reference concrete structure.

In this paper, we assume that local resources will be used to produce CLT. Larch (Larix gmelinii) is the main species grown in Northeast China. According to the design code in China, the strength properties of local species are similar to C22 timber specified in British Standard [24]. To dimension the CLT structural components in the substitution structures, grade C22 wood is assumed to be used. Although the structural weight of the CLT substitution building is less than that of the concrete reference building, the foundation was not redesigned in this paper.

In order to meet fire resistance requirements, gypsum plasterboards were used. In the design, 15 and $30 \mathrm{~mm}$ plasterboards were used for 60 and $90 \mathrm{~min}$ ' fire resistance, respectively. Details of the envelopes of the substitution CLT structures in different locations are illustrated in Figure 6. For the envelope design in Harbin, the thickness of the insulation layer was increased to $100 \mathrm{~mm}$ from $50 \mathrm{~mm}$ and one layer of $120 \mathrm{~mm}$ thick brick was also added so as to satisfy the building regulation in China [21].

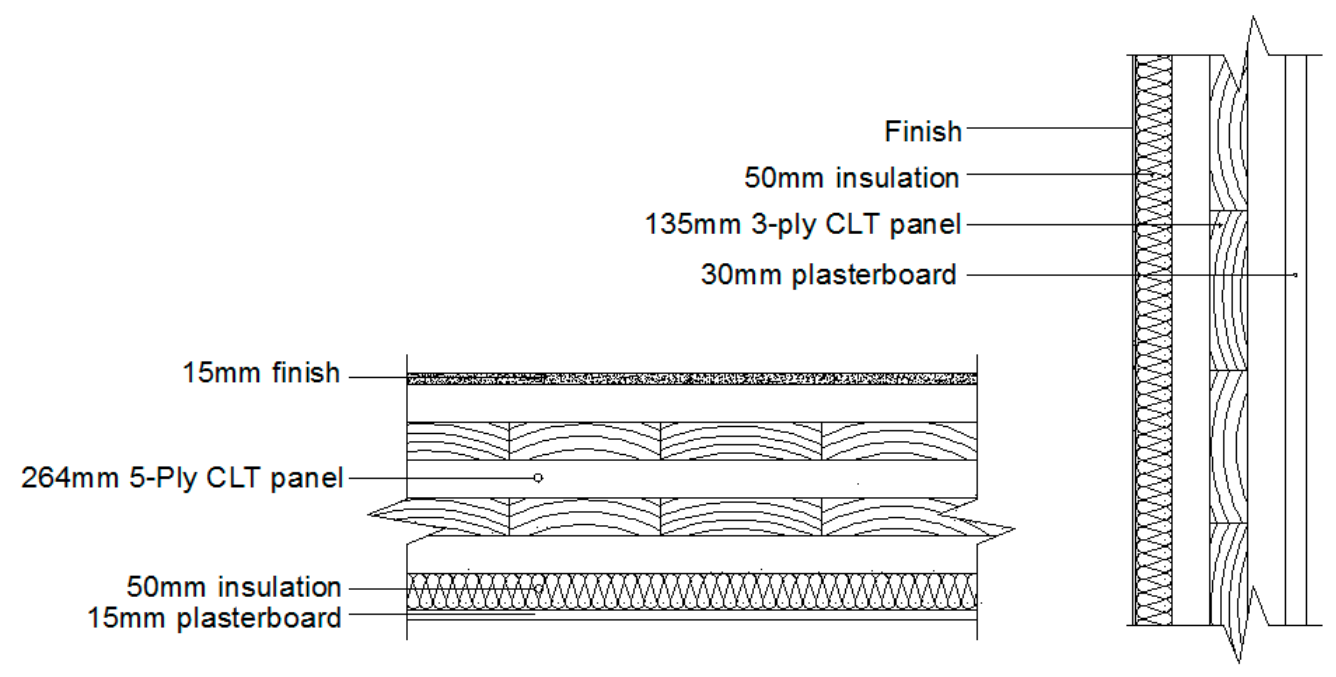

Figure 6. Details of walls and floor for CLT structures according to building regulation in Xi'an.

\section{Life-Cycle Assessment Framework}

\subsection{The Framework}

Life-cycle assessment (LCA), also called cradle-to-grave assessment, is a method used to evaluate the environmental effect, energy consumption and sometimes the cost of a production [25]. One branch of the LCA method is life-cycle energy analysis (LCEA), which is commonly used in the construction industry. The whole process of building construction, from materialisation and operation to end-of-life stage of the buildings, is considered when it is carried out. Although there have been some simple methods developed for architects to carry out fast LCA, such as that proposed by Hollberg and Ruth [26], building construction is a complicated process and often not all the details in all the locations could be obtained to put into the analysis. For example, some analyses only include the materialisation process [27]. It is therefore essential to define the boundary of the analyses when carrying out LCA or LCEA, Figure 7 depicts the boundary of analyses in this study.

Assurance of data quality in an LCA is the first step towards obtaining realistic and reliable results, so reliable and local data should be used whenever possible. This local data should be updated regularly so as to ensure its accuracy [28]. In this paper, local data, such as concrete materials, local practice, and transportation, etc., is used whenever possible [29-33]. In China, a database has been created to provide accurate data for life-cycle analyses and some of the data in this study is extracted 
from this database [30]. The production and construction of CLT is still in its infancy stage in China, therefore the data used in this paper is taken from research outputs from North America [34].

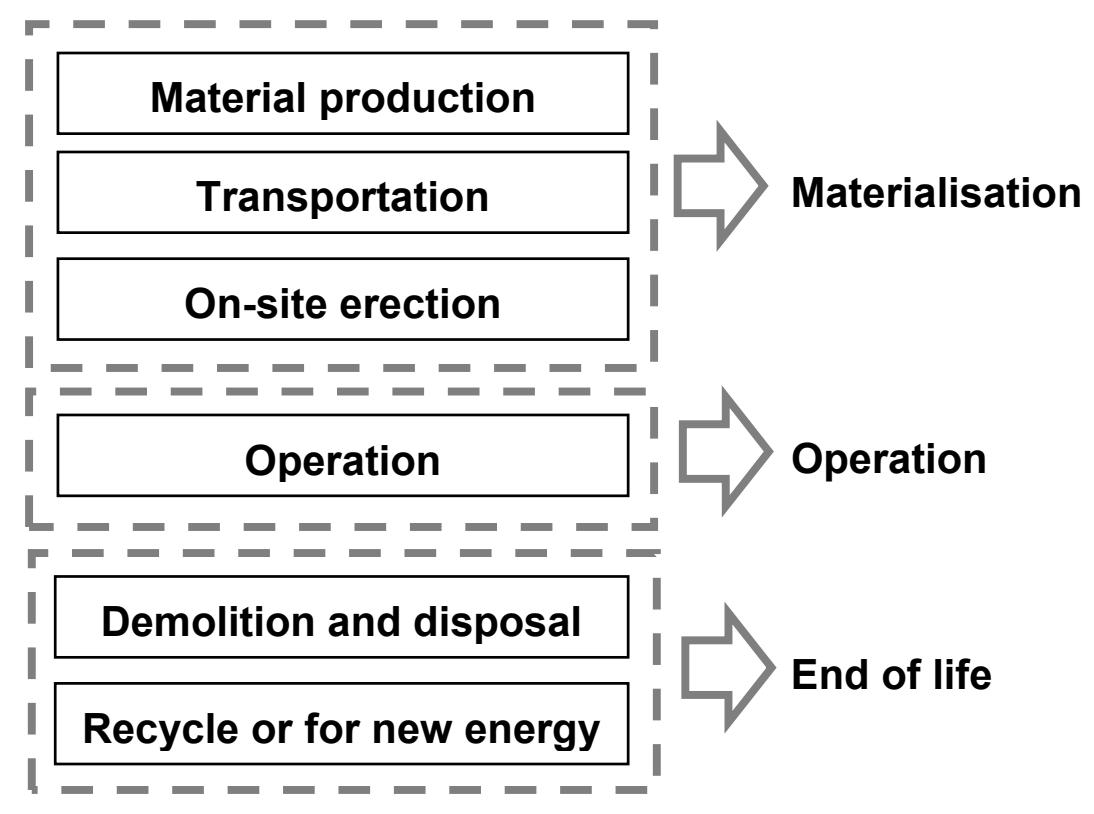

Figure 7. System boundary for life-cycle analysis.

\subsection{Materialisation Stage}

The materialisation stage comprises material production, transportation and on-site erection. Several assumptions were made when carrying out the LCA in the materialisation stage:

(1) Energy consumed and carbon emission produced by decoration of concrete structures were neglected.

(2) Fasteners for construction of CLT were not considered due to the small amount of volume when compare with CLT panels.

(3) The carbon sequestration of CLT is considered in the assessment with the assumption that 1 cubic metre of timber would store $800 \mathrm{~kg}$ of $\mathrm{CO}_{2}$.

(4) Erection of CLT buildings is set to be $20 \mathrm{MJ} / \mathrm{m}^{2}$ [8].

(5) The boundary of the materials including concrete, sand, cement, steel and brick start from the extraction of the raw materials, whereas that for CLT starts from harvesting the tree.

Table 1 summarises the inventory of data used in calculating the life-cycle assessment.

Table 1. Inventory of resources used in materialisation stage.

\begin{tabular}{cccc}
\hline Products & Function Units & Value & Reference \\
\hline Concrete & $\mathrm{GJ} / \mathrm{t}$ & 0.764 & {$[29]$} \\
Sand & $\mathrm{GJ} / \mathrm{t}$ & 0.029 & {$[30]$} \\
Cement & $\mathrm{GJ} / \mathrm{t}$ & 3.186 & {$[31]$} \\
Steel & $\mathrm{GJ} / \mathrm{t}$ & 19.52 & {$[32]$} \\
Brick & $\mathrm{GJ} / \mathrm{t}$ & 0.218 & {$[33]$} \\
CLT & $\mathrm{GJ} / \mathrm{m}^{3}$ & 0.545 & {$[34]$} \\
Gypsum board & $\mathrm{GJ} / \mathrm{m}^{3}$ & 2.400 & {$[30]$} \\
Expanded polystyrene & $\mathrm{GJ} / \mathrm{t}$ & 94.00 & {$[35]$} \\
Transportation (train) & $\mathrm{MJ} / \mathrm{t} \cdot \mathrm{km}$ & 0.220 & {$[36]$} \\
Transportation (lorries) & $\mathrm{MJ} / \mathrm{t} \cdot \mathrm{km}$ & 2.300 & {$[36]$} \\
\hline
\end{tabular}




\subsection{Operation Stage (Modelling Approach and Its Assumptions)}

Energy consumption in the operation stage was obtained by simulation. Commercialised software IES $^{\mathrm{TM}}$ (Integrated Environmental Solution) was used to simulate the energy used in this study. The concrete and CLT buildings in both Harbin and Xi'an were simulated and their details were as described in the previous sections. The life spans of the buildings were assumed to be 50 years; the outputs of the analyses were considered as energy consumed in the operation stages. The following assumptions were made when analysing energy consumption during operation:

(1) Only energy used for heating, cooling and lighting is simulated.

(2) The locations of windows are not changed when altering CLT from concrete and therefore the lighting requirements are not changed.

(3) The indoor temperature is controlled between $18{ }^{\circ} \mathrm{C}$ and $26^{\circ} \mathrm{C}$ in all rooms except for balconies. The lights were assumed to be switched on in bedrooms between 21:00-24:00 and in living rooms between 18:00 to 21:00.

(4) Internal heat gain was assumed to be $90 \mathrm{~W}$ per person

(5) Areas for staircases are not heated or cooled.

(6) The ventilation rate is assumed to be $30 \mathrm{~m}^{3}$ per hour per person.

(7) Electricity is used for cooling and lighting whereas coal is used for heating. This is the current practice in China.

\subsection{End-of-Life Stage}

The end-of-life stage consists of demolition, disposal and recycle. An investigation has shown that the energy for demolition of a building can be assumed to be $90 \%$ of the energy required in the erection phase in China [37] In this paper, recycling the reusable material for other construction or production can be offset against the energy consumption and $\mathrm{CO}_{2}$ for producing it. Apart from being reused or recycled, timber can also be used as biofuel to provide energy, and this is taken into account when analysing the energy balance. When calculating the life-cycle assessment in this study, it is assumed that for the concrete reference buildings in both Harbin and Xi'an all the concrete and steel materials after demolition go into landfill and the recycle rate for the bricks is assumed as $60 \%$. The reason for concrete to go into landfill is that, although the recycle aggregate could shift carbon and energy for the next project, benefit would hugely depend on the transportation distance between the recycling plant and the construction site and therefore tends to be limited [38]. For the CLT building in both cities, a recycle rate of $55 \%$ is assumed with $45 \%$ used for biomass energy. Different recycle rates will be discussed in a later section.

\section{Results and Discussion}

\subsection{Quality of Data and Uncertainties of the Assessment}

As described earlier, the data used to carry out life-cycle assessment was domestic whenever possible. However, some information, such as CLT production, is not available in China. This is due to the fact that currently there is only one CLT factory in China and essential information for life-cycle analyses has not been collected at this stage. In this paper, the data was obtained from that of North America. One can expect that, at this stage, efficiency of the CLT factory in China would not be as high as that in those countries with experience of mass production, such as Canada and Austria. However, this situation will improve with more factories being set up in China and more experiences having been learned. It is noteworthy that the CLT production does not account for a large proportion of energy consumption for the whole procedure, and therefore making this assumption will not have a significant effect on the results.

Timber has the advantages of having light weight, and therefore, with the same structural height and area, timber buildings would require less material and strength for foundations. This benefit 
would start to be significant when the structures become taller. Substantial works would be required in the cases where tall concrete structures are built or buildings are located in areas where soil conditions are not good. This factor is not considered in this study as there are too many uncertainties involved. Another important factor to consider is that due to the trend of tall timber buildings, there will be more and more timber buildings exceeding the height of 10-storeys. This will start to make it challenging in engineering the structure, and there might be some other structural elements, such as bracing or structural damper, needing to be adopted. These adoptions would affect the assessment results in the "materialisation" stage. This study only considers a seven-storey platform CLT structure, as there has been sufficient precedent for this structural form.

There are other uncertainties that would affect the results in the operation stage, including the opening and structural height for each floor. One should notice that the opening of the concrete and CLT buildings are assumed to be identical and this assumption would eliminate the re-design of the lighting in the buildings and therefore keep the variation from lighting minimal. Higher inter-storey height would require more energy to heat and cool the rooms.

\subsection{Energy Consumptions and $\mathrm{CO}_{2}$ Emissions}

The comparative energy consumption of reference and CLT buildings in Xi'an and Harbin is summarised in Figure 8. It is clear that the operation stage is the major period of energy consumption of the buildings, accounting for at least $80 \%$ in four scenarios. It is particularly significant in the case of the concrete building in Harbin. This is because Harbin is considered a severe cold region where temperatures can go down to as low as $-20^{\circ} \mathrm{F}$ during the winter time, and therefore heating contributes to the main portion of the energy consumption.

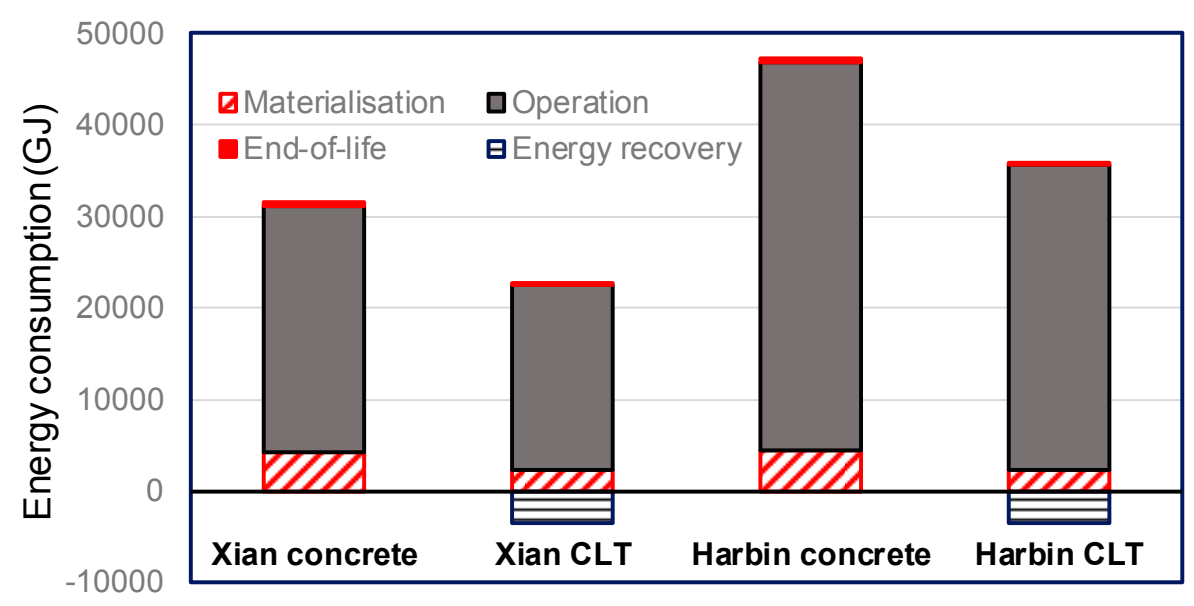

Figure 8. Comparison of energy consumption of concrete and CLT buildings in both cities.

The results show that in both cities, the energy consumption of the CLT building is more than $30 \%$ lower than that of the concrete reference building in both $\mathrm{Xi}^{\prime}$ an $(39.4 \%)$ and Harbin (31.6\%) over the period of 50 years if the energy recovery from using timber as biofuel at the end of life is considered. The energy consumption of concrete and CLT buildings in both cities for conditions that consider $45 \%$ of the CLT is used as biofuel is summarised in Table 2.

Table 2. Energy consumption per area of concrete and CLT buildings in Xi'an and Harbin over 50 years.

\begin{tabular}{ccc}
\hline & Xi'an $\left(\mathrm{GJ} / \mathbf{m}^{\mathbf{2}}\right)$ & Harbin $\left(\mathrm{GJ} / \mathbf{m}^{\mathbf{2}}\right)$ \\
\hline Concrete & 11.29 & 16.90 \\
CLT & 6.84 & 11.56 \\
\hline
\end{tabular}


The $\mathrm{CO}_{2}$ emissions of reference concrete buildings and CLT buildings in both $\mathrm{Xi}^{\prime}$ an and Harbin are different over the 50 years, as shown in Figure 9. There are several reasons for these differences. In the materialisation stage, timber requires less energy to extract compared with other carbon intensive materials, such as concrete and steel in the reference building. During the operation stage, the CLT building in both cities have lower U-values compared with reference buildings, and hence need less energy for heating. Consequently, this reduces the carbon emission as has been explained previously-i.e., heating in China mainly relies on energy generated by coal. In the end-of-life stage, substantial parts of the CLT buildings could be recycled and therefore carbon emissions for CLT buildings are offset.

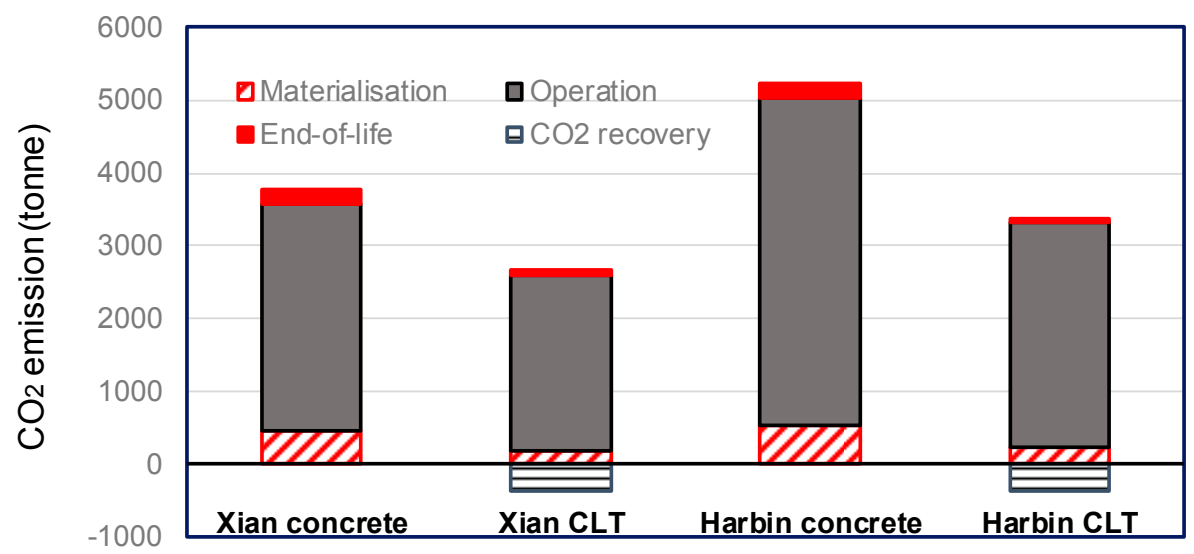

Figure 9. Comparison of $\mathrm{CO}_{2}$ emissions of concrete and CLT buildings in both cities.

Similar phenomena can be found in that the $\mathrm{CO}_{2}$ emissions in the operation stage contribute the major part of the $\mathrm{CO}_{2}$, at least $80 \%$. It is more obvious for the concrete building in Harbin, where at least $85 \%$ of carbon comes from operation, mainly heating of the building. In the cold region in China, heating mainly uses energy generated from coal, which is the major carbon emitter. Figure 9 also shows that carbon emissions of both concrete and CLT buildings in Harbin are higher than those in Xi'an. This is because of the extreme weather of Harbin in the winter time. In terms of carbon emissions of buildings with consideration of carbon offset of CLT, carbon emissions would be reduced by $39.3 \%$ in Xi'an if CLT were used to replace concrete, and the figure changes to $42.3 \%$ in Harbin. Table 3 summarises the $\mathrm{CO}_{2}$ emissions per area with different recycling scenarios of CLT buildings and their comparison with concrete buildings. It shows that if $90 \%$ of the CLT is recycled in the next project, $\mathrm{CO}_{2}$ emissions would be reduced by more than $46 \%$ in both cities. When considering the carbon storage in timber, the timber would store more carbon in itself (606.24 ton) than those emitted during the process of materialisation and end-of-life stages, which account for 245.9 ton in $\mathrm{Xi}^{\prime}$ an and 274.3 ton in Harbin.

Table 3. Carbon emissions per area of concrete and CLT buildings in both cities over the period of 50 years with different recycle ratio for timber.

\begin{tabular}{cccc}
\hline CLT Recycling Ratio & Material & Xi'an $^{\prime}\left(\mathbf{t} / \mathbf{m}^{\mathbf{2}}\right)$ & Harbin $\left(\mathbf{t} / \mathbf{m}^{\mathbf{2}}\right)$ \\
\hline NA & Concrete & 1.35 & 1.87 \\
$55 \%$ & CLT & 0.82 & 1.07 \\
$90 \%$ & CLT & 0.73 & 0.99 \\
\hline
\end{tabular}

\subsection{Forest Resource Distribution in China}

In China, the recorded forest area was 195.5 million hectares in 2008, which accounts for $20.4 \%$ of the national land area, with the figure increasing to $22.2 \%$ by 2015 . The forest coverage ratio 
of this country is still far below the global average of $31 \%$, and therefore it is important that the Chinese government implement an efficient forest management strategy to find the balance between utilising timber as a construction material to realise the ambition the Chinese government has set in environmental sustainability and ensuring the forest area coverage remains in its uptrend.

In the life-cycle assessment in this paper, the transportation distances in both cities were assumed to be $300 \mathrm{~km}$, which implies that the CLT factories are located within the same province. Figure 10 shows the capital cities of Heilongjiang and Shaanxi Provinces and the surrounding forest. In Heilongjiang Province, the north part is dominated by larch, whereas birch dominates the middle Heilongjiang. In southern Heilongjian the main tree species include birch, maple and basswood. In Shaanxi Province the main wood species are Shensi fir (Abies chensiensis), Norway Srpuce (Picea abies), Chinese red pine (Pinus tabulaeformis) and Chinese white pine (Pinus armandii). Figure 10 shows that with a proper forest management strategy in place there should be sufficient forest to provide material for making CLT. In particular, Northeast China possesses large forest resources accounting for $26.9 \%$ of the total forest area of China.
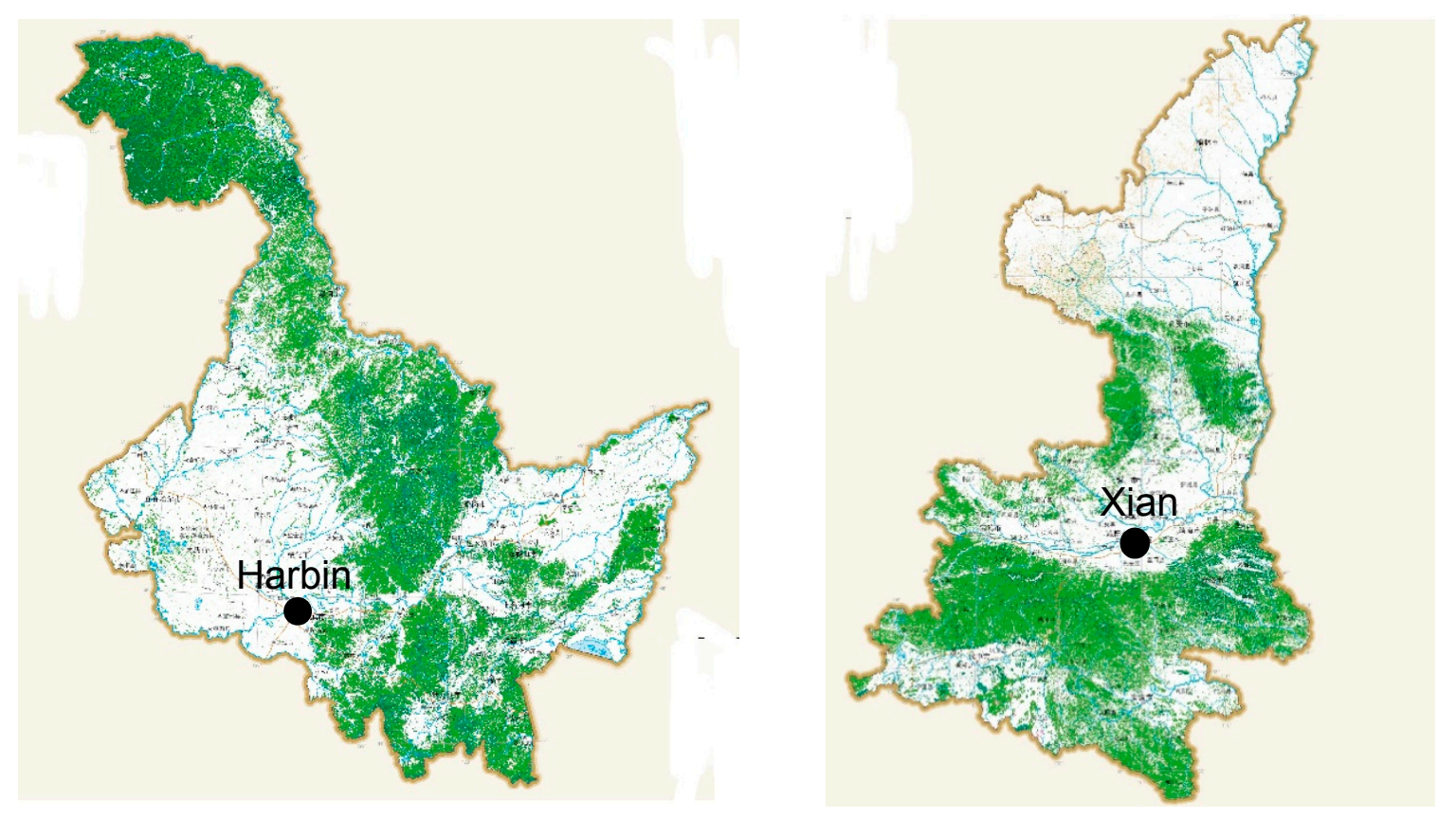

Figure 10. Forest distribution in Xi'an and Harbin.

\subsection{Legal Implementations}

While modern timber building technologies have experienced considerable growth in Europe, Australia, Canada, and Japan, the use of timber has not been widely adopted in China and industrial uptake is still limited. Most timber buildings in China are light-weight frame buildings. There are several legal issues that prevent using CLT to replace existing construction materials in mid-rise residential buildings, two of which are the standards for CLT manufacturing and the height limit of the timber structures in building codes in China.

Currently there is only limited manufacturing capacity for CLT in China, and the standards for manufacturing CLT using local resources are still under development. Before more CLT factories are built and local resources are used, CLT building in replacement of existing construction materials can only rely on those materials imported from either North America or Central Europe, and this in consequence reduces the energy saving. Another important issue is the height limit of timber structures in China, which is limited to up to three-storeys. The main reason, as has been explained previously, is that most of the timber buildings are light-weight timber framed structures and therefore have inherent higher fire risk. Figure 11 shows the height limit of timber structures around the world. 
It can be seen that many countries, such as Canada, Australia, and some European countries had a height limit of three-storeys for timber buildings in 2002 and most of these countries have released this limitation to more than six stories. Therefore, to release the height limit in China in the next revision of building codes is essential so as to benefit from the energy saving and carbon reduction induced from timber.
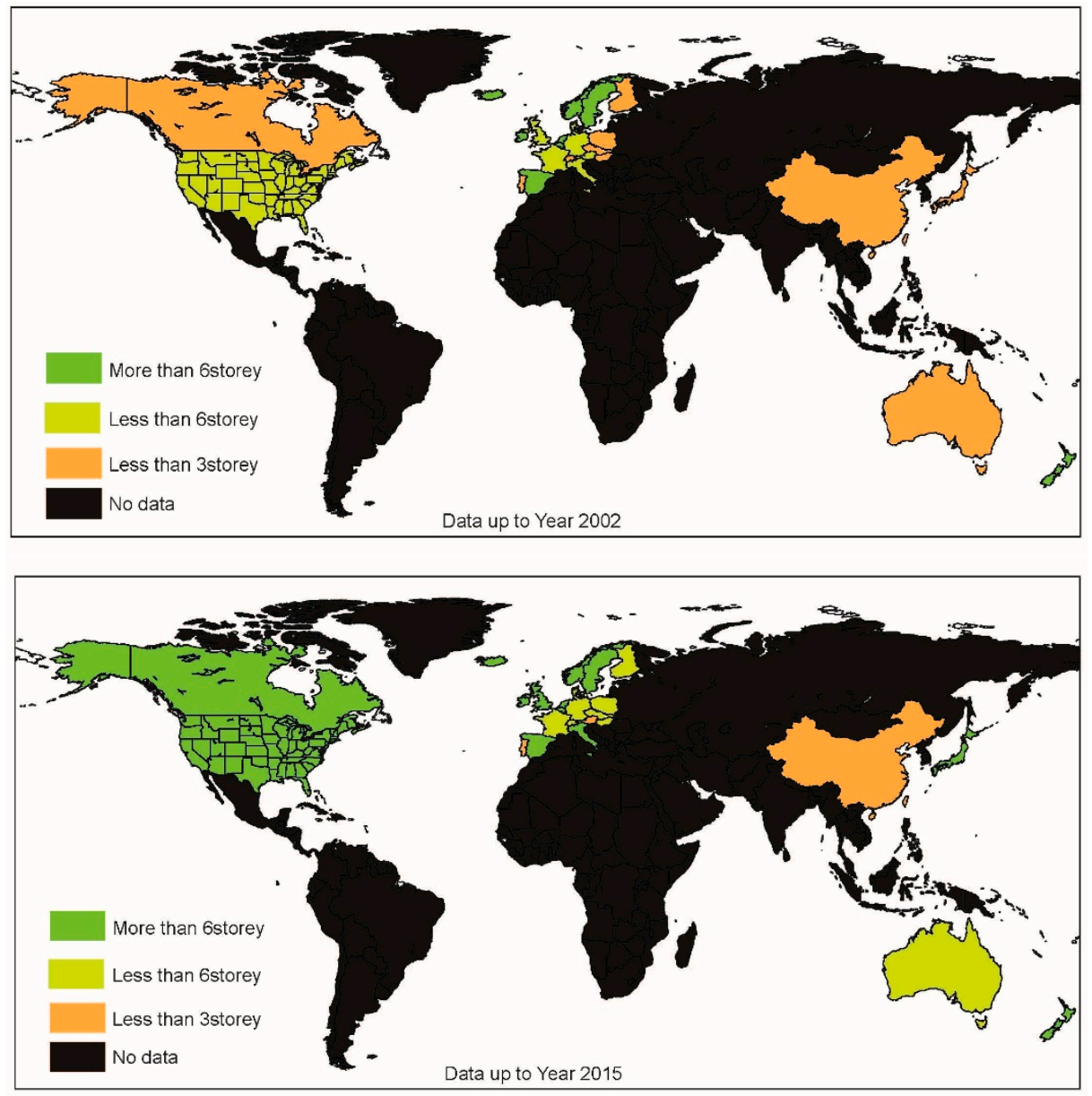

Figure 11. Map of timber height limits in the world.

\section{Conclusions}

This paper examines the potential to use CLT as an alternative construction material to carbon and energy intensive construction materials, such as concrete. A cradle-to-grave life-cycle assessment was carried out in a reference building in both $\mathrm{Xi}^{\prime}$ an and Harbin with the same structural layout but with different materials (concrete and CLT), so as to compare the energy consumption and carbon emissions of these buildings over a period of 50 years. The results have shown that in Xi'an, CLT buildings would save $36.4 \%$ energy and reduce carbon emission by $42.9 \%$, in the case where $55 \%$ of the CLT being recycled at the end of the project. In the case of Harbin, there would be a reduction of $32.3 \%$ in energy consumption and $45 \%$ in carbon emissions. This paper also draws the conclusion that higher recycling rates for CLT at the end of the life of the building would further reduce carbon emission of the buildings during their life spans.

Acknowledgments: Part of the works in this paper were supported by National Natural Science Foundation of China (NSFC: 51608144), the paper was also made possible due to the financial support (Grant number: (2015) 3069) from the China Scholarship Council in supporting Haibo Guo to work with Wen-Shao Chang in the UK. 
Author Contributions: Cheng Sun and Haibo Guo collected and made comments on the darft, Haibo Guo and Ying Liu analysed the data, drafted and revised the manuscript. Wen-Shao Chang supervised the overall project. All authors read and approved the manuscript and author contributions.

Conflicts of Interest: The authors declare no conflict of interest.

\section{References}

1. Chau, C.K.; Hui, W.K.; Ng, W.Y.; Powell, G. Assessment of $\mathrm{CO}_{2}$ emissions reduction in high-rise concrete office buildings using different material use options. Resour. Conserv. Recycl. 2012, 61, 22-34. [CrossRef]

2. Wang, H.; Zhang, R.; Liu, M.; Bi, J. The carbon emissions of Chinese cities. Atmos. Chem. Phys. 2012, 12, 6197-6206. [CrossRef]

3. Yu, X.; Qu, H. The role of China's renewable powers against climate change during the 12th Five-Year and until 2020. Renew. Sustain. Energy Rev. 2013, 22, 401-409. [CrossRef]

4. Zhang, Z. Assessing China's carbon intensity pledge for 2020: Stringency and credibility issues and their implications. Environ. Econ. Policy Stud. 2011, 13, 219-235. [CrossRef]

5. Ministry of Housing and Urban-Rural Development. Action Plan to Promote Green Building Materials Production and Building Applications; China Construction Industry Publishing House: Beijing, China, 2015. (In Chinese)

6. Lo, K. China's low-carbon city initiatives: The implementation gap and the limits of the target responsibility system. Habitat Int. 2014, 42, 236-244. [CrossRef]

7. Dijk, M.; Blom, I.; Salet, T.; Marinus, P. Environmental impact as a parameter in concrete structure parametric associative models. Constr. Build. Mater. 2014, 67, 360-365. [CrossRef]

8. Gong, X.; Nie, Z.; Wang, Z.; Cui, S.; Gao, F.; Zuo, T. Life cycle energy consumption and carbon dioxide emission of residential building designs in Beijing. J. Ind. Ecol. 2012, 16, 576-587. [CrossRef]

9. Eriksson, P.E. Comparative LCAs for wood and other construction methods. In Proceedings of the World Conference on Timber Engineering, Lahti, Finland, 14-17 June 2004.

10. Gustavsson, L.; Sathre, R. Variability in energy and carbon dioxide balances of wood and concrete building materials. Build. Environ. 2006, 41, 940-951. [CrossRef]

11. Pacheco-Torgal, F.; Cabeza, L.; Labrincha, J.; De Magalhaes, A. Comparing the environmental impact of reinforced concrete and wooden structures. In Eco-Efficient Construction and Building Materials: Life Cycle Assessment (LCA), Eco-Labelling and Case Studies; Guardigli, L., Ed.; Woodhead Publishing Limited: Cambridge, UK, 2014; pp. 407-433.

12. Mallo, M.F.L.; Espinoza, O.A. Outlook for cross-laminated timber in the United States. BioResources 2014, 9, 7427-7443.

13. Crespell, P.; Gagnon, S. Cross Laminated Timber: A primer; Fpinnovations: Vancouver, QC, Canada, 2010.

14. Stanić, A.; Hudobivnik, B.; Brank, B. Economic-design optimization of cross laminated timber plates with ribs. Compos. Struct. 2016, 154, 527-537. [CrossRef]

15. Lineham, S.A.; Thomson, D.; Bartlett, A.I.; Bisby, L.A.; Hadden, R.M. Structural response of fire-exposed cross-laminated timber beams under sustained loads. Fire Saf. J. 2016, 85, 23-34. [CrossRef]

16. Sikora, K.S.; McPolin, D.O.; Harte, A.M. Effects of the thickness of cross-laminated timber (CLT) panels made from Irish Sitka spruce on mechanical performance in bending and shear. Constr. Build. Mater. 2016, 116, 141-150. [CrossRef]

17. Aicher, S.; Hirsch, M.; Christian, Z. Hybrid cross-laminated timber plates with beech wood cross-layers. Constr. Build. Mater. 2016, 124, 1007-1018. [CrossRef]

18. Khavari, A.M.; Pei, S.; Tabares-Velasco, P.C. Energy Consumption Analysis of Multistory Cross-Laminated Timber Residential Buildings: A Comparative Study. J. Archit. Eng. 2016, 22, 04016002. [CrossRef]

19. Harley, T.; White, G.; Dowdall, A.; Bawcombe, J.; McRobie, A.; Steinke, R. Dalston Lane-The world's tallest CLT building. In Proceedings of the World Conference on Timber Engineering (WCTE 2016), Vienna, Austria, 22-25 August 2016.

20. Ministry of Housing and Urban-Rural Development. Code for Design of Civil Buildings (GB 50352-2005); China Construction Industry Publishing House: Beijing, China, 2005. (In Chinese)

21. Ministry of Housing and Urban-Rural Development. Energy Conservation Design Standard for New Heating Residential Buildings (JGJ26-2010); China Construction Industry Publishing House: Beijing, China, 2010. (In Chinese) 
22. European Committee for Standardization (CEN). Eurocode 5 Design of Timber Structures—Part 1-1: General Rules and Rules for Buildings; European Committee for Standardization: Bruxelles, Belgium, 2003.

23. Timber Research and Development Association (TRADA). Cross-Laminated Timber (Eurocode 5) Design Guide for Project Feasibility; TRADA Technology: London, UK, 2009.

24. British Standard Insitute. Structural Timber, Strength Classes; British Standards Institute: London, UK, 2009.

25. Cabeza, L.F.; Rincón, L.; Vilariño, V.; Pérez, G.; Castell, A. Life cycle assessment (LCA) and life cycle energy analysis (LCEA) of buildings and the building sector: A review. Renew. Sustain. Energy Rev. 2014, 29, $394-416$. [CrossRef]

26. Hollberg, A.; Ruth, J. LCA in architectural design-A parametric approach. Int. J. Life Cycle Assess. 2016. [CrossRef]

27. Robertson, A.B.; Lam, F.C.; Cole, R.J. A comparative cradle-to-gate life cycle assessment of mid-rise office building construction alternatives: Laminated timber or reinforced concrete. Buildings 2012, 2, 245-270. [CrossRef]

28. Hong, J.; Shen, G.Q.; Peng, Y.; Mao, C. Uncertainty analysis for measuring greenhouse gas emissions in the building construction phase: A case study in China. J. Clean. Prod. 2016, 129, 183-195. [CrossRef]

29. Zhou, X.X.; Song, Z.L. The life cycle assessment of two kinds of concretes. Environ. Eng. 2009, S1, $472-475$. (In Chinese)

30. IKE. Chinese Life Cycle Database-CLCD (2016). Available online: http://www.ike-global.com/products2/chinese-lca-database-clcd (accessed on 9 June 2016).

31. Sui, X. Exergetic Life-Cycle Assessment of Cement Production Processes. Master's Thesis, Dalian University of Technology, Dalian, China, 2014.

32. Wang, L.S.; Zhang, L.F. Life Cycle assessment of environmental impacts for the whole steel production process. China Popul. Resour. Environ. 2012, 22, 239-244.

33. Li, Q.J.; Liu, J. Lifecycle energy consumption and carbon emissions of aerated concrete block and sintered shale hollow brick. J. Chongqing Coll. Electron. Eng. 2015, 24, 148-151. (In Chinese)

34. Athena Sustainable Materials Institute (ASMI). A Life Cycle Assessment of Cross-Laminated Timber Produced in Canada; Athena Sustainable Materials Institute: Ottawa, ON, Canada, 2013.

35. Li, Z.; Gong, X.Z.; Wang, Z.H.; Liu, Y.; Ma, L.P.; Wang, S.P.; Guo, J. Life cycle assessment of rock wool board and EPS board. Mater. Sci. Forum 2014. [CrossRef]

36. Spielmann, M.; Scholz, R. Life cycle inventories of transport services: Background data for freight transport. Int. J. Life Cycle Assess. 2005, 10, 85-94. [CrossRef]

37. Zhang, X. Carbon Emissions Measurement Methods and Comparative Studies on Green Building Structural System. Master's Thesis, Harbin Institute of Technology, Harbin, China, 2014.

38. Marinković, S.; Radonjanin, V.; Malešev, M.; Ignjatović, I. Comparative environmental assessment of natural and recycled aggregate concrete. Waste Manag. 2010, 30, 2255-2264. [CrossRef] 